\title{
Heidegger desgarrado. El papel de la diferencia en la concepción de Ereignis
}

\author{
(Heidegger disrupted. The role of \\ difference in the concept of Ereignis)
}

\author{
Abraham RuBín
}

Recibido: 18 de mayo de 2012

Aceptado: 20 de noviembre de 2012

\section{Resumen}

En este artículo se desarrolla el papel que cumple la diferencia en la construcción del concepto de Ereignis. Pese a la insistencia de Heidegger en el predominio que la identidad tiene sobre la diferencia, el artículo tratará de detectar el rumor insistente que la diferencia produce en su obra y cuáles son sus puntos de cristalización en el Ereignis, analizando cómo el propio Heidegger se ve, a veces, viviendo en sí mismo el desgarro que la propia diferencia lleva consigo.

Palabras clave: diferencia, Ereignis, identidad, acontecimiento.

\begin{abstract}
This article will cover the role of difference in the development of the concept of Ereignis. Despite Heidegger's insistence on the supremacy identity has over difference, this piece will try and locate the persistent rumor that difference evokes in his works and its crystalization points in Ereignis, analyzing how Heidegger sometimes sees his very self living inside the disruption that difference implies.
\end{abstract}

Keywords: Difference, Ereignis, Identity, Event. 


\section{Introducción}

Cabría preguntarse si el acontecimiento existía antes de que Heidegger lo pensase. Es, naturalmente, una pregunta legítima, pero lleva a una de las aporías típicas en las que el realismo hace caer a la fenomenología, corriente filosófica a la que Heidegger pertenecía y en razón de la cual, como veremos, surge en el siglo XX un concepto como acontecimiento. Ciertamente, la fenomenología clásica considera que nada es fuera de la relación con un sujeto, sin que por ello tenga que ser considerado como subjetivo. Por eso, aquellos que consideran que lo que propiamente es existe ahí fuera independientemente de nuestra experiencia, están presuponiendo una realidad efectiva con la que simplemente nos relacionaríamos lingüísticamente a base de decir enunciados susceptibles de adecuarse -verdaderos- o de no adecuarse a ella -falsos-. Pues bien, para Heidegger que algo sea no se reduce a que sea efectivamente real. Es más, se podría considerar todo su pensamiento como una lucha afanosa contra esta reducción del ser a la realidad efectiva. Y justamente lo que surge de ese afán es "el pensamiento del acontecimiento", así, como correlación. Es decir, el pensar acontece y el acontecimiento se piensa, lo que viene a significar a grandes rasgos que el acontecimiento es en la experiencia que tenemos de él. O, respondiendo a la pregunta inicial, el acontecimiento es lo que por antonomasia no existe, esto es, lo que no es susceptible de ser pensado en términos de realidad efectiva, o lo que se piensa como siendo cuando no se piensa en dichos términos.

Como se ve, las dificultades para decir el acontecimiento no son de partida menospreciables. Si a eso sumamos que para Heidegger ya no sólo no era un concepto sino que ni siquiera funcionaba a modo de término que mantuviese un significado fijo, aplicable desde fuera -o incluso, cabría decir, intertextualmente- a los diferentes momentos en los que él recurría a la palabra, entonces, deberíamos renunciar a toda pretensión de abarcarlo. La obra de Heidegger, lo que él llamaba su "camino del pensar" es todo menos sistemática, pero sin embargo, ese "todo" contiene ciertos rasgos -que no atributos- con los que se puede trazar la silueta de la sombra del acontecimiento al amanecer. Y si, siguiendo apenas unos segundos más con la metáfora del desplazamiento, ese primer rayo de luz fue fenomenológico, lo importante en el tema que nos ocupa es que produjo sombra.

\section{Ereignis o acontecimiento apropiador}

Sirva como indicador de las implicaciones que tiene operar desde la sombra, ese primer momento en que Heidegger se introdujo en ella, la primera vez que la palabra "acontecimiento" surge en el camino del pensar... Nos remontamos al año 1919, a las primeras lecciones del joven Heidegger, unos quince años antes de que 
el acontecimiento se convierta en un motivo central de su pensamiento, con los efectos que ello pudiera haber tenido. Anda a vueltas con una crítica a la teoría y, por tanto, a esa verdad como adecuación de la que hablamos anteriormente, y en el fondo, ya, con una crítica a la posición fenomenológica de su maestro Husserl. Contrapone "acontecimiento" (Ereignis) y "proceso" (Vorgang): Este último remitiría a una concepción del correlato fenomenológico en el que algo, un objeto, una quididad, pasa -fijándose y representándose- por delante de un sujeto cognoscente. Acontecimiento, por el contrario, es una vivencia -previa a todo acto teórico y a la que éste siempre remite- que no es representable, sino que yo mismo me apropio la vivencia en tanto que ella acontece haciéndose propia conforme a su esencia. Aquí no nos queda más remedio que remitirnos a la palabra alemana Ereignis, porque Heidegger pretende con ella un gesto único en el que se aúna el que algo ocurra, suceda, acontezca y la experiencia de que algo se vuelva propio, propiamente propio, abriendo, por así decir, un sentido o significatividad. Por eso, se suele traducir Ereignis no simplemente como "acontecimiento", sino como "acontecimiento apropiador", sentido que el mismo Heidegger enfatiza muchas veces con un guión, Er-eignis: «Las vivencias son Er-eignisse (acontecimientos apropiadores), en la medida en que viven desde lo propio (Eigenen) y sólo así la vida vive»1.

Por el camino de su pensar, Heidegger va a ir dejándole espacio al acontecimiento y, para ello, deshaciéndose no sólo de "sujeto", de "teoría", de "conocimiento" y de "conciencia", sino también de "yo", de "vivencia", de "comprensión", de "vida", del plural de acontecimiento, de "sentido"... pero aún así ese gesto que él quiere único con la palabra Ereignis, y que tenemos que desglosar en dos, en acontecimiento y en apropiación, permanece en todo su pensamiento posterior del acontecimiento. En uno de los pocos textos - pocos en comparación con la producción esotérica- en el que intenta acercar el pensamiento del acontecimiento a sus contemporáneos, ya a finales de la década de los cincuenta, Heidegger no sólo hará uso de esta etimología ficticia, por la que asocia el morfema -eign- con das Eigene, lo propio. También se siente apoyado en la recurrencia al término Ereignis, después de haber estado unos veinticinco años madurándolo, por su supuesta etimología real: «Er-eignen significa originariamente: asir con los ojos (er-äugen), esto es, divisar, llamar con la mirada, a-propiar» ${ }^{2}$. Así, este er-äugen, que viene de Auge (ojo), conecta con el sentido corriente que asocia Ereignis a fantasma (Erscheinung) y a la manifestación (Anzeichen) o el indicio (Zeichen) que tenemos de los acontecimientos, asumiendo ese significado señalado por Heidegger de "mostrarse súbitamente", "ponerse súbitamente ante los ojos" o "asir con la mirada".

\footnotetext{
1 Heidegger (1987), p. 75.

2 Heidegger (1988a), p. 87.
} 
Por tanto, en Ereignis Heidegger concentra varios sentidos: el de "acontecimiento", el de "propio"; y también hace referencia a lo que aparece, a una manifestación o indicio3.

\section{Decir el acontecimiento}

Ahora bien, es oportuno ahora perfilar la situación en la que el pensamiento del acontecimiento se encuentra. La crítica a la fenomenología desde la fenomenología es también la crítica de la teoría desde la teoría, la crítica de la metafísica desde la metafísica o, en otras palabras, la crítica de la filosofía desde la filosofía. Y el caso es que no por hablar de pensamiento hemos solucionado el problema. Pero, ¿cuál es el problema? Nosotros lo llamaríamos "decir".

Nos encontramos en los límites de un discurso, el filosófico, que se está cuestionando a sí mismo como decir, que está poniendo sobre la mesa el hecho mismo de que decir "es" le resulta un problema, aun a pesar de que -o precisamente porque- como discurso se fundamenta en tener que (poder) decirlo. Quizás podamos ver esto con un poco de detalle.

\subsection{Ser y decir}

En Sein und Zeit, su célebre obra publicada en 1927, Heidegger arranca preguntando, como ya había hecho Aristóteles, ¿qué es el ser? Esta pregunta, que filosóficamente sería la más vieja de todas, según Heidegger no tiene todavía una respuesta, permaneciendo envuelta en vaguedades y generalidades. Se debería esto a que la pregunta se ha formulado mal, sin dirección alguna. En consecuencia, Heidegger quiere enfocar de nuevo ese interrogante sin prejuicios de ningún tipo.

En el apartado $\$ 2$ dice: «Lo puesto en cuestión en la pregunta que tenemos que elaborar es el ser, aquello que determina al ente en cuanto ente, eso con vistas a lo cual el ente, en cualquier forma que se lo considere, ya es comprendido siempre. El ser del ente no "es", él mismo, un ente»4.

Este punto de arranque es lo que se conoce como diferencia ontológica, y es lo que provoca que la respuesta a la pregunta ¿qué es el ser? no pueda ser una respuesta al uso. El ser determina al ente, pero no es un ente y, al intentar decirlo, en principio, se lo ontifica.

\footnotetext{
3 Cfr. Polt (2005), Spinosa (2005) y Vallega-Neu (2010), passim. Asimismo, para ver las conexiones entre el Ereignis y la filosofía francesa de la segunda mitad del s. XX, que parten de esta relación, cfr., especialmente, Rolli (2004), passim.

${ }^{4}$ Heidegger (1977), p. 6.
} 
Con esto vemos el problema al que se enfrenta todo pensamiento que quiera advertir lo planteado por Heidegger, ya que toda filosofía es un cierto decir. Y en cada decir nos encontramos con que algo se dice de algo. Y es esta separación, esta brecha entre lo que se dice y aquello de lo que se dice lo que siempre se escapa en cada decir. Este es, asimismo, el intento de decir el ser. Según Heidegger ${ }^{5}-y$, especialmente, según Felipe Martínez Marzoa ${ }^{6}$, uno de los intérpretes que con mayor claridad y seriedad ha sabido desplegar el vínculo fundamental del pensamiento heideggeriano con la filosofía griega- esta problemática está en relación directa con lo tratado en Aristóteles con el nombre de apóphansis.

\subsection{El decir y el ser en Aristóteles}

En primer lugar, tal vez, habría que decir que Aristóteles es, seguramente, el primer filósofo que realiza una teoría de la significación, es decir, la separación -y a su vez la relación- que existe entre el lenguaje como signo y el ser como significado. De hecho, en el De interpretatione, Aristóteles distingue entre el discurso general y la proposición, siendo ésta subtipo de aquél y lo único susceptible de considerarse verdadera o falsa, por referirse a la existencia 7 .

Para Aristóteles, «una proposición (prótasis) es un enunciado (lógos) que afirma (kataphatikós) o niega (apophatikós) algo sobre algo (ti katá tinos)»8.

La interpretación que Marzoa -siguiendo a Heidegger- propone parte de la definición aristotélica de enunciado, donde el Estagirita afirma que «no todo enunciado es apofántico (apophantikós) ${ }^{9}$ sino [sólo] aquel en que se da la verdad y la falsedad; y no en todos se da» ${ }^{10}$. Aquí está en juego la etimología de apóphansis -revelación, manifestación-, que se relaciona con verbos como apophaíno (mostrar, declarar, dar a conocer o revelar) o phaíno (dar luz, encender, hacer visible, mostrar, manifestar, etc.), y que se emplea para argumentar lo siguiente:

En el momento en el que decimos algo de algo, se manifiesta, aparece eso que llamamos ser. En una articulación, digamos, del estilo "A es B", estos dos términos significarían lo siguiente: B es aquello que decimos y A aquello de lo que lo decimos, y lo que estamos haciendo pues es unir dos elementos que son distintos e identificarlos, sacarlos de su movimiento original en el que tienen sentido, en el que son

\footnotetext{
5 Op. cit., § 33, pp. 153 y ss.

6 Cfr., especialmente, Martínez Marzoa (2000a), pp. 11-26, 149-158 y 203-210; Martínez Marzoa (2000b), pp. 11-17 y 121-133; o Martínez Marzoa (1999), pp. 7-15.

7 Aristóteles (1988), 3, 16b, 19.

8 Op. cit., I, 24a: 15-6.

9 Miguel Candel lo traduce, en la edición citada, por "declarativo" o "asertivo".

10 Op. cit., 17a: 2-7.
} 
lo que son. Lo que es lo mismo que decir que la cópula une a la vez que separa, mienta como iguales dos términos en tanto que dos, es decir, distintos: dice a la vez ser y no-ser.

Discrepa de Marzoa -y Heidegger- Pierre Aubenque, para quien, pese a que Aristóteles efectivamente utiliza la palabra apóphansis para referir a la proposición, esto no justifica, a su juicio, que se atribuya al discurso una función apofántica, esto es, reveladora, ya que la expresión únicamente se refiere a aquel discurso que «dividiendo y componiendo es susceptible de verdad o falsedad»11. Por tanto, la apóphansis pertenece exclusivamente al juicio y no al discurso en general, y un pensamiento sobre el ser será en primer lugar una palabra sobre el ser y nos obligará a analizar la relación ambigua que tienen el lenguaje y las cosas, es decir, su presencia ausente, esa distancia que une y separa ${ }^{12}$.

En todo caso, Aristóteles reconoce una pluralidad de significaciones del ser, ya desde Sobre las refutaciones sofísticas ${ }^{13}$. A partir de ahí, y ya en la Metafísica, el Estagirita estableció las siguientes diferencias14: tó eînai (hecho de ser), tò ón (ente) ${ }^{15}$, tò tí ên eînai ("lo que era y en lo que permanece el ser", esencia), tò tí esti (quididad) y tóde ti ("algo determinado", individuo concreto) ${ }^{16}$.

Según Aristóteles, pese a que el conocimiento comienza cuando los sentidos captan el individuo (tóde ti), la epistéme estudia cómo los seres que existen (tà ónta) se clasifican en virtud de su esencia o su género. Por otra parte está la ciencia que estudia el "ser" común a todos los entes independientemente del género al que pertenezcan. Esta es la ciencia del ente en tanto que ente (tò ón he ón $)^{17}$, que no busca sino averiguar qué es el ser y/o qué es el ente (tí tò ón).

A decir de Heidegger, Aristóteles responde a esta pregunta caracterizando lo que él llamará "dimensión onto-teológica de la metafísica", pues el ser se referirá tanto a la ousía -sea ésta lo individual o la esencia, es decir, la "sustancia primera" (próte ousía) o la "sustancia segunda" (deútera ousía) - como a lo divino (tò theîon). Esta doble vertiente, que dominará toda la filosofía tradicional posterior a Aristóteles, se

\footnotetext{
11 Aubenque (1974), p. 108.

12 Cfr. Op. cit., p. 115.

13 Aristóteles (1982), 10, 170b.

14 Seguimos la traducción de García Yebra en Aristóteles (1998), en cuyo prólogo se da cuenta del calibre de la empresa realizada, apareciendo asimismo las discrepancias de otros autores al respecto de las traducciones escogidas en la edición española.

15 Marzoa discrepa, siguiendo a Heidegger, pues si aceptamos que convencionalmente kalós se traduce por "bello" y agathós por "bueno", entonces to kalón no es ni "lo bello" ni "el bello" sino "la belleza" y tò agathón no "lo bueno" ni "el bueno" sino "el bien". Correspondientemente tò ón sería algo así como "el ser". Cfr. Martínez Marzoa (2000a), p. 14.

16 Aquí Marzoa traduce por "esto". Cfr. Op. cit., pp. 150-151. Otras distinciones de Aristóteles son las de génos (género) y eîdos (especie). Cfr. Aristóteles (1998), libro III.

17 Op. cit., IV, 1, 1003a21-26.
} 
olvidará, a juicio de Heidegger, justamente de la multiplicidad aristotélica, es decir, de la respuesta dada por éste a la unidad con la que en el primer inicio Parménides había empezado a pensar el ser. Y en este giro, por el que se deja de atender al tratamiento del ser en su unidad como algo múltiple, la indistinción griega encarnada en tò ón entre ser y ente se convierte, a ojos de Heidegger, en la incapacidad metafísica para pensar la diferencia ontológica.

Aubenque ${ }^{18}$, por su parte, acentúa el hecho de que Aristóteles, del mismo modo que rechazaba la radical equivocidad del ser de los sofistas, también rechaza su univocidad, es decir, el entenderlo simplemente como esencia. Es por ello por lo que distingue entre "significación atributiva" (kath’henós) y "significación esencial" (semainein hén) ${ }^{19}$, lo que confiere la posibilidad de que también la esencia pueda atribuirse -a decir de Aristóteles en los Analíticos segundos, «predicados que significan la esencia» ${ }^{20}$. La clave estará en las distintas significaciones que se le den a la cópula "ser", a saber, al menos "ser por sí" (kath 'autó) y "ser por accidente" (katá symbebekós $)^{21}$. Esta problemática desemboca en la resolución aristotélica del problema de la predicación -las relaciones entre el uno y lo múltiple- que, como es sabido, se fundamenta en la distinción entre "ser en potencia" y "ser en acto" y aterriza en la enumeración de las categorías como la cristalización de la pluralidad de los tipos de atribución, es decir, como los distintos sentidos de ser que hay además del ser en potencia y el ser en acto22.

En cuanto a la teoría sobre la verdad, de lo dicho anteriormente Aristóteles colige que el ser en cuanto verdadero lo único que hace es repetir en el pensamiento lo que se expresa en las categorías ${ }^{23}$. Pero esta no es la única concepción de la verdad que Aristóteles propone, como Aubenque también nos recuerda 24 .

Además de pensar la verdad del ser como un enlace del pensamiento -en Metafísica, VI, 4-, concepción que asumiría que lo verdadero y lo falso no son sino funciones lógicas del juicio, Aristóteles también introduce una concepción ontológica de la verdad -en Metafisica, IX, 10-: aquí la verdad no solo remitiría al pensamiento sino también a las cosas, ya que la verdad se encontraría en el ser-enlazado o el ser-separado de las cosas, es decir, «estar juntas o separadas» 25 . Por tanto, la verdad sería desvelar una verdad antepredicativa más fundamental (o previa). Y esto, además, solamente va a respectar a los seres compuestos, objeto de enuncia-

\footnotetext{
18 Aubenque (1974), pp. 137-138.

19 Aristóteles (1998), IV, 4, 1006b15.

20 Aristóteles (1988), I, 22, 83a24.

21 Aristóteles (1998), IV, 7, $1017 \mathrm{a} 7$.

22 Aubenque (1974), pp. 155-159.

${ }^{23}$ Aristóteles (1998), VI, 4, 1028a1.

24 Aubenque (1974), p. 160.

25 Aristóteles (1998), IX, 10, 1051b2.
} 
ción pero no de atribución ${ }^{26}$, es decir, «sería simplemente la palabra humana a través de la cual se desvela la verdad del ser» 27.

Esta segunda propuesta es la que, a juicio de Heidegger, conforma la cumbre del pensamiento de Aristóteles acerca del ser del ente, y por ello profundiza en la misma a partir del análisis de alétheia ${ }^{28}$, alátheia y aletheíe, donde $a-$ es un prefijo negativo, de privación, y el lexema -léth-o -lâth-viene del verbo lanthánein o lantháno, esto es, permanecer oculto. Es decir, que "verdad" nombra en negativo aquello que permanece oculto, es decir, lo verdadero es lo que se desoculta en tanto que algo sigue oculto.

De este modo, en la visión heideggeriana, todo trata de un decir, de un decir originario que separa un intervalo en el que las cosas son en tanto dejan de pertenecer a algo de lo que se separan. El decir sería dejar que tengan lugar las cosas, el juntarse algo con algo, enfrentándose algo con algo.

La pregunta heideggeriana por el sentido del ser que sostiene esta tensión ante el valor copulativo de dicho verbo derivará unos años después de Sein und Zeit en el ya referido pensamiento del acontecimiento. Con el gesto de decir "es" se le escapa a la filosofía eso que quiere decir, que considera que sí es. El acontecimiento heideggeriano, retomando lo que dijimos anteriormente, se podría entender así como eso que se escapa al "es", pero que de alguna manera tiene que ser dicho, sustentado por la pretensión filosófica de decirlo, por el hecho de que la filosofía no es otra cosa que un discurso. Pero entonces, en ese sentido, el acontecimiento ya es en sí mismo el hecho mismo de decirlo, de decir -el "es"- de otra manera.

\subsection{Decir la filosofía}

Esto, sin duda, trae consigo una nueva forma de hacer filosofía, en la que la proposición -con su cópula- ya no es el núcleo alrededor del que todo gira. En vez de conceptos hay palabras-signo que remiten a algo ausente; la coherencia formal de la argumentación se sustituye por rodeos con los que poder mostrar aquello que no se deja decir; los adverbios, las preposiciones, los prefijos y sufijos, las asociaciones semánticas, o incluso un vocabulario sacado de la vida cotidiana, adquieren el mayor protagonismo en el lenguaje heideggeriano. Pero, con todo, el hecho de que el que el acontecimiento sea dependa en esa forma tan sutil del modo en que se diga, en la precariedad del correlato fenomenológico, de la relación sin relata, hace que todo pequeño matiz determine la comprensión del todo. Y en el caso de Heidegger, esa pretensión filosófica, ese gesto tan sutil de poderío filosófico, a pesar de todo el

\footnotetext{
26 Op. cit., IX, 10, $1051 \mathrm{~b} 24$.

27 Aubenque (1974), p. 160.

28 Cfr, por ejemplo, Heidegger (2004), passim; cfr., también, Heidegger (2003), pp. 336-342.
} 
vuelco lingüístico, y aun cuando sin dicha voluntad tal vez no estaríamos hablando aquí de acontecimiento, ese "poder decir" que lleva hasta el límite -legitimándose en él- el parmenídeo "ser y pensar" de la filosofía, exige, en su correlación, que el acontecimiento aparezca, es decir, que sea.

"Decir", para Heidegger, significa "hacer aparecer" y, por tanto, a pesar de todas las dificultades, de todas las imposibilidades y obstáculos inherentes a cualquier camino que sea "digno" de llevar tal nombre, parece que se trata de un "yo, el pensador, puedo". Lo que esto trae como consecuencia es esa extraña comprensión del acontecimiento como un acontecimiento de la filosofía 29 , como si el acontecimiento no dependiese de nada ni de nadie más que del pensador - a excepción del poeta, que, con todo, es un caso aparte-, como si la historia de Occidente estuviese determinada por los actos filosóficos de Platón, Aristóteles, Descartes, Hegel, Nietzsche y, en última instancia, Heidegger. Pareciera que el ego philosophicus, como fundamento desfondado, hubiese cerrado todas las vías para salir fuera de sí. En este recorrido filosófico, Heidegger asumirá que cada pensador que marca época utiliza un concepto central que no es más que su manera de pensar el ser y su intento, por tanto, de decir el acontecimiento. Con este gesto unifica la historia de la filosofía y a cada pensador consigo mismo, en un lazo que cierra las diferencias alrededor de la identidad.

Uno de los muchos esquemas propuestos por Heidegger es el que recoge su obra Nietzsche, en la que desde el concepto de voluntad de poder nietzscheano reconstruye en una unidad la historia de la metafísica: lo que en Platón es la idea y en Aristóteles la enérgeia pasa a ser en Descartes subjetividad para llegar a la concepción de ser como voluntad, que marca todo el desarrollo de la filosofía moderna hasta su fin, esto es, pasando por Leibniz -ser como mónada (unidad de perceptio y appetitus)-, apareciendo en Kant y Fichte como voluntad-razón, manteniéndose y desarrollándose en Schelling y Hegel, transformándose en Schopenhauer (al pensar el mundo como voluntad y representación) hasta desembocar en Nietzsche (ser primigenio: voluntad de poder $)^{30}$.

\section{La simultaneidad del Ereignis}

Pero para entender mejor esta relación que existe en Heidegger entre el aparecer del acontecimiento y el poder del pensador, vamos a hablar ahora de uno de los rasgos recurrentes en todo el pensamiento del acontecimiento. Se trata de la simultaneidad, lo que en griego se señalaba con la partícula "háma". Si algo nos dice la

\footnotetext{
29 Esta impresión la ofrece la obra más conocida de Heidegger sobre el acontecimiento, escrita entre 1936 y 1938: Heidegger (1994), passim.

30 El esquema completo se desarrolla en Heidegger (1997), pp. 455 y ss.
} 
palabra acontecimiento es que es incontrolable, que no se puede predecir, que ocurre sin que alguien pueda provocarlo, y fuera de toda relación causal en tanto predeterminante de una necesidad. El acontecimiento es, pues, contingente, y por ello, de alguna manera, tienen que coincidir de forma casual ciertos factores independientes para que algo ocurra, sin que uno cause al otro. La simultaneidad, ese ocurrir a la vez que se nos escapa y que asimismo podría evitar toda relación de causalidad o de condicionamiento, parece entonces que tendría que jugar un papel importante en la configuración del acontecimiento. En Heidegger, de hecho, lo juega, porque su pensamiento del Ereignis constituye un giro con respecto al proyecto trascendental de Sein und Zeit. En la medida en que quiere eliminar todo rastro de trascendentalidad, de aprioricidad, piensa el acontecimiento como la simultaneidad espaciotemporal de ser, ente y existente humano (Dasein) ${ }^{31}$. Puesto que todos ocurren a la vez, ninguno puede condicionar al otro, y justamente en tanto que son al mismo tiempo hay acontecimiento. Tal vez sea preciso detenernos en este punto.

\subsection{Acontecimiento como apertura}

En los Beiträge zur Philosophie, la primera y más célebre obra de su producción esotérica escrita entre 1936 y 1938, Heidegger quiere dejar de considerar el ser desde la perspectiva del ente y como fundamento del mismo ${ }^{32}$. «De allí que éste [el ser] ya no pueda ser pensado (gedacht) a partir del ente; tiene que ser pensado (erdacht) desde él mismo» ${ }^{33}$. Heidegger distingue este nuevo sentido de ser también en la escritura: El ser en relación con el ente es Sein, el ser desde sí mismo es Seyn. La diferencia entre ente y ser es sintetizada en la expresión «Seiendes ist, Seyn west $»:$ El ente es, el ser se hace presente» ${ }^{34}$. Este hacerse presente es el acontecimiento: «Esto es el hacerse presente (Wesung) del ser mismo. Nosotros lo llamamos Ereignis» 35 .

Pero, ¿qué es el Ereignis en realidad? El Ereignis no es algo objetivo. Tampoco puede ser considerado como un hecho (Begebenheit) ${ }^{36}$. El Ereignis sería más bien el acto de acaecer, y ese acaecer se haría siempre en la tensión diferencial que separa algo que llega a la presencia con lo que queda más allá de ella. Es por eso por lo que Heidegger en otro lugar 37 relaciona Wesen con el antiguo wesan (permanecer,

\footnotetext{
31 Cfr. Heidegger (1994), pp. 65, 13, 223, y 289.

32 Cfr. Berciano (1991b), passim; cfr., también, Berciano (1991a), pp. 281-360.

33 Heidegger (1994), p. 7.

34 Op. cit., p. 30.

35 Op. cit., p. 7.

36 Op. cit., pp. 256-263.

37 Heidegger (1971), p. 143.
} 
durar), pero también con an-wesen (estar presente) y ab-wesen (estar ausente). «De este modo el ser (Seyn) es el acontecimiento del acto de acaecer (das Er-eignis der Er-eignung), el $D a$, eso abierto, en el que él mismo se estremece»38. Aquí $D a$ no referiría a aquí o allí sino a la apertura del ser. De aquí se derivaría Da-sein: «Dasein es la permanencia del hacerse presente de la verdad del ser» ${ }^{39}$. Esta apertura se considera al mismo tiempo que el ser como acontecimiento. «El hacerse presente (Wesung) del ser como Ereignis implica el acto de acaecer (Er-eignung) el Dasein» ${ }^{40}$. El hacerse presente del ser es el que constituye el $D a$ o apertura, es su origen $(E r-)$.

La apertura que acaece en el hacerse presente el ser es también la verdad originaria o la iluminación (Lichtung). Ésta no es para Heidegger pura apertura o desocultación sino, como ya vimos, simultánea ocultación 41 .

Otra forma de caracterizar la apertura en la que tiene lugar el acontecimiento parte del tiempo-espacio. Por ejemplo en: «Es el acontecimiento del acto de acaecer el Da-sein (Ereignis der Ereignung des Da-seins) aquello en lo cual se funda el paraje tranquilo, el juego tiempo-espacio (Zeit-Spiel-Raum) del pasar de lado el desprotegido "en medio", que desencadena la tormenta del acto de acaecer» ${ }^{42}$. Asimismo también habla de Fügung, de ensamble de tiempo y espacio; de espaciar temporalizador y de temporalización espaciadora (zeitigendes Räumen - räumende Zeitigung) 43 .

Además, Heidegger utilizará en los Beiträge un esquema de simultaneidad:



38 Heidegger (1994), p. 239.

39 Op. cit., p. 311.

40 Op. cit., p. 254.

41 Esta simultaneidad de iluminación o desocultación y ocultación es afirmada constantemente, por ejemplo, como relevante preámbulo a los Beiträge, en el artículo "Der Ursprung des Kunstwerkes", incluido en Heidegger (2003), pp. 1-74.

42 Heidegger (1994), p. 243.

43 Op. cit., p. 261. 
En el esquema hay una dirección vertical en la que están presentes los conceptos de mundo (Welt) y tierra (Erde) -que harían referencia a lo abierto y lo cerrado respectivamente, desocultación y ocultación-, que luchan entre sí en la apertura originaria del Ereignis: «El paraje del instante se hace presente a partir de éste (del Ereignis) como la lucha de tierra y mundo. La disputa de la lucha es el Da-sein» ${ }^{44}$.

Esto nos remite de nuevo a Sein und Zeit, donde la analítica existenciaria del Dasein nos guiaba en la pregunta por el sentido del ser. El Da indicaba la apertura, el espacio abierto que se daba en el ser humano; pues según Heidegger el ser humano (Mensch) es el verdadero lugar de la apertura, el lugar donde la apertura se vuelve real y concreta y toma forma. Este ser-apertura es la verdadera esencia del ser humano. "¿Quién es el ser humano? Aquél que es usado por el ser (Seyn) para sostener el hacerse presente de la verdad del ser (Seyn). Sólo en tanto que usado de este modo el ser humano "es" ser humano, en tanto está fundado por el Da-sein, es decir, creando se torna él mismo fundador del Da-sein. /

Pero el ser (Seyn) está al mismo tiempo concebido aquí como Ereignis»45.

Es decir, el ser humano aparece como fundador del Dasein (en él se da la apertura), pero, al mismo tiempo, es un ente temporal, lo que provoca que el ser humano sea fundado y fundamento al mismo tiempo. Según Heidegger, «en la fundamentación de la verdad del ser (Seyn) de alguna manera está en juego el ser humano y, con todo, vuelve a no estarlo»46. Difíciles palabras que hacen que permanezca la oscuridad alrededor del fundamento del ser, más allá de la apertura del Ereignis.

Y precisamente en este punto es donde conviene hablar del otro elemento del esquema que veíamos anteriormente, a saber, los dioses (Götter). Dios siempre se ha referido al fundamento último de la metafísica. Por ello Heidegger, que no se refiere a un politeísmo ni a nada semejante con la expresión "dioses", utiliza ésta para contraponerla al Ente supremo de la metafísica. Los dioses referirían a una pluralidad de fundamentos. Pero esto es un problema para pensar el ser como Ereignis. Según Heidegger, «sólo si nos damos cuenta de la necesidad exclusiva del ser y de que no se hace presente como el Dios; sólo cuando hayamos puesto en consonancia nuestra esencia con estos abismos entre el ser humano y el ser y entre el ser y los dioses, sólo entonces empezarán a ser reales los prerrequisitos para una historia. Por eso sólo tiene valor la reflexión sobre el Ereignis» 47 . En otras palabras, el verdadero fundamento es la apertura. Heidegger permanece, así, en el Ereignis, en un acontecimiento que es simultaneidad, una múltiple interrelación: mundo, tierra, ser humano, dioses.

\footnotetext{
44 Op. cit., p. 30.

45 Op. cit., p. 318.

46 Op. cit., p. 313.

47 Op. cit., p. 26.
} 


\subsection{Identidad en el Ereignis: Ge-stell $y$ Sammlung}

En esta línea, la relación entre el ser y el ser humano se podría considerar la relación fundamental sobre la que Heidegger siempre vuelve. Por eso es crucial aquí ahondar en la simultaneidad que se da de ambos en el acontecimiento. En Der Satz der Identität ${ }^{48}$ nos la presenta ya enmarcada en el contexto de nuestra propia época, la de la técnica.

En este texto se desarrolla el modo en que ser y ser humano forman una constelación a partir de la lectura heideggeriana de la identidad. Ésta no toma a la identidad como una propiedad del ser sino, en cierto modo, al ser como parte de la identidad. Siguiendo el célebre verso de Parménides del que se asume la identidad entre ser y pensar, Heidegger lee que el ser y el pensar -es decir, el ser humano ${ }^{49}-$ tienen lugar en lo mismo, una mismidad a partir de la cual ser y pensar se pertenecen. Esto es lo que sucede con el ser y el ser humano - pensar-, pues ninguno de los dos tiene preeminencia sobre el otro -el ser humano no es anterior al ser, pero el ser necesita al ser humano para la apertura del Dasein gracias a la cual llegará a la presencia-. En la época de Heidegger, cuya característica fundamental es el dominio de la técnica, el olvido del ser llega a su máxima expresión. El pensador alemán utiliza la palabra com-posición ${ }^{50}$ (Ge-stell) para referirse a la única experiencia que podemos tener de la mismidad que hace que ser y ser humano se pertenezcan, es decir, la esencia misma de la técnica.

Retomando el célebre aserto de Hölderlin «donde hay peligro, crece lo que nos salva» ${ }^{51}$, Heidegger señala el carácter doloroso de la esencia de la técnica -la máxima retracción del ser-, el Ge-stell del que será preciso sobreponerse (Verwindung) para abrirse a la llegada de aquello que preludia, a saber, el modo de relación más propio y originario entre ser y ser humano, que Heidegger llama Ereignis. «En la com-posición (Ge-stell) domina un raro unir y dedicar (Vereignen und Zueignen). Se trata de experimentar llanamente ese apropiar (eignen), en el cual ser humano y ser son apropiados mutuamente; esto es, se trata de entrar en aquello que nosotros llamamos el acontecimiento (Ereignis)» ${ }^{52}$. Así, la com-posición sería un preludio del acontecimiento ${ }^{53} \mathrm{o}$, al menos, la puerta de entrada de la alteridad en la mismidad, que llevaría a un acontecer más originario: el Ereignis.

\footnotetext{
48 Heidegger (1988a), pp. 60-96.

49 El propio Heidegger establece este vínculo entre el pensar parmenídeo y el ser humano: «Al entender el pensar como lo distintivo del ser humano, estamos recordando una mutua pertenencia que atañe al ser humano y al ser». Op. cit., p. 73.

50 Seguimos la traducción de Helena Cortés y Arturo Leyte en la edición citada.

51 «Wo aber Gefahr ist, wächst / Das Rettende auch». Hölderlin (2002), p. 212.

52 Heideggr (1988a), p. 24.

53 Op. cit., p. 25.
} 
Lo relevante no es que el ser y el ser humano se pertenezcan el uno al otro, sino que hay un "poner en común", remarcado por el guión que separa el prefijo Ge- del verbo stellen, que no es presente, sino que refiere a un "pertenecer" más originario. Y el acontecimiento sería ese "dejar pertenecer", lo que ha permitido que ocurra la historia del ser, es decir, la historia de la metafísica, repleta de épocas en las que el ser se da de determinada forma. Por ello el Ereignis pasa a ser el pensamiento rector heideggeriano, que necesita primero deshacerse del lenguaje metafísico que lo imposibilita -ser, ente, sujeto, objeto, etc.- para poder alcanzarlo. De acuerdo con esto «el Ereignis es el ámbito en sí mismo oscilante, mediante el cual el ser humano y el ser se alcanzan el uno al otro en su esencia y adquieren lo que les es esencial al perder las determinaciones que les prestó la metafísica» 54 .

Ahora bien, Heidegger no pierde de vista la relación con la identidad, y afirma que aquello que nombra el Ereignis «acontece sólo en la unidad, esto es, ni siquiera en un número, sino de modo único» 55 .

Para acercarnos de otra manera a la identidad tomaremos el concepto clave de Sammlung ("reunión" o "recogimiento"), que Heidegger logra articular de forma especialmente clara en un pequeño texto titulado Was heißt Lesen?56

Allí podemos leer: «¿Qué significa leer? Lo que porta (Das Tragende) y guía en el leer es la reunión (Sammlung) $>57$. Tal vez la reunión y el recogimiento sean conceptos que nos puedan facilitar el camino a la comprensión de la simultaneidad. Es decir, es la reunión del ser y el ser humano en el Ereignis lo que provoca acontecimiento, y es el recogimiento del ser humano en el ser lo que prologa al Ereignis. Desde esta perspectiva la Sammlung resuelve la escisión originaria, también en lo que refiere al habla y a la lectura. Heidegger dice: «Dilucidar el habla quiere decir no tanto llevarla a ella, sino a nosotros mismos al lugar de su esencia, a saber: al recogimiento (Versammlung) en el acontecimiento (Ereignis)» ${ }^{58}$.

Y en ese recogimiento, además de encontrarnos con aquello que decíamos era el pensamiento rector en Heidegger (Ereignis), se retoma una problemática decisiva en su interpretación de la historia de la metafísica: el lógos. Pues lógos refiere también a cierta reunión, a cierto juntar, es decir, a un reunir y enlazar: «Significa lo que quiere decir nuestro homónimo "legen"; poner abajo y poner delante. Aquí prevalece el juntar, el verbo latino "legere" como leer en el sentido de ir a buscar y juntar. Propiamente "légein" significa el poner abajo y poner delante que se reúne a sí mismo y recoge otras cosas. Empleado en la voz media "légesthai" quiere decir:

\footnotetext{
54 Op. cit., p. 26

55 Op. cit., p. 25.

56 Heidegger (2002), pp. 111-116.

57 Op. cit., p. 111. Una interpretación diferencial de este texto la encontramos en Vidarte (2006), pp. $15-68$

58 Heidegger (1959), p. 12.
} 
tenderse en el recogimiento (Sammlung) del reposo»59. El lógos, pues, junta, ensambla, reúne aquello que nos encontramos en la búsqueda y que se desoculta de la brecha en la que se situaba originalmente y que deja atrás en su desvelamiento, en tanto en cuanto hay algo más que permanece oculto. Ésta es la concepción que Heidegger afirma que Heráclito tenía del ser, o lo que es lo mismo, cómo el ser se desvela en el pensamiento de Heráclito a través de la palabra lógos, que asume el papel de posada, el albergar, el resguardar, allí donde se le da cobijo a lo recolectado, a lo reunido, a lo que se (nos) ha desocultado. Asimismo: «En el pensar de Heráclito aparece el ser (presencia) del ente como lógos, como la posada que recoge y liga. Pero este destello del Ser permanece olvidado» ${ }^{60}$.

Se trata de nuevo, de un decir, de cierto decir originario en el que las cosas son, un decir (Sage) que desoculta, que es un mostrar (Zeigen). El ser humano pertenece a ese Decir y es quien lo escucha. Escuchando ese Decir aparece la oportunidad de su llegada, pero previamente a ese llegar está el dejar(se)-pertenecer, la simultaneidad original. Y en ese mostrar del decir es donde se percibe el Ereignis 61 . Es más, «¿Y si el Ereignis -nadie sabe cuando ni cómo- se hiciera in-tuito (Ein-Blick) cuyo fulgor iluminante entra en aquello en lo que es y en lo que se toma por ente? ¿Y si por esta su entrada el Ereignis sustrajera todo lo presente de su sujeción a la mera disponibilidad y lo devolviera a lo que le es propio?» 62

\subsection{Diferencia en el Ereignis: Austrag}

Lo que vemos asimismo con la predominancia de la pertenencia es cómo la resolución, la unión, la reunión o la identidad parecen ir aventajando a aquello que dejan atrás y que entendíamos con el nombre de "diferencia" (ontológica), y que con el pensamiento del Ereignis es algo que pasa a un segundo plano.

El paso se da claramente en Identität und Differenz, donde ya vimos cómo el acontecer ocurría en la unidad, pero es si cabe más explícito en el prólogo a la obra, donde Heidegger indica que la pertenencia de identidad y diferencia se muestra como aquello que hay que pensar, pero apela a que el lector descubra de qué manera la diferencia procede de la esencia de la identidad, y como pista a tener en cuenta cita la armonía existente entre el Ereignis y el Austrag63.

A pesar de que éste se acostumbra a traducir por "resolución", "distribución", "arreglo", etc., Heidegger lo utiliza, entre otros términos, para referir a la diferen-

\footnotetext{
59 Heidegger (1954), p. 200.

60 Op. cit., p. 214.

61 Heidegger (1959), p. 258.

62 Op. cit., p. 264.

63 Cfr. Heidegger (1988a), pp. 56-58.
} 
cia que aparece y que se resuelve en el Ereignis, o en el claro (Lichtung) en el que surge.

Austrag pertenece a la familia léxica de tragen (portar, llevar, sostener), y su etimología nos dice mucho de lo que está en juego: portar una di-ferencia -lat: fero (portar)- en un "entre", en un umbral en el que siempre se puede buscar la resolución o el desgarro 64 .

Pero quizá lo justo no sería resolver el umbral hacia un adentro o hacia un afuera, pues tal vez la verdad no se encuentre en ninguno de estos lugares, sino que resida en el propio tránsito de la diferencia entre adentro y afuera. En esa diferencia, también en esa inseguridad e inestabilidad, encuentra todo su sentido el umbral, un límite entre un origen y un final, de nuevo un adentro y un afuera, de nuevo la diferencia entre algo que se dice y algo de lo que se dice y, siempre de nuevo, la completa imposibilidad de que se produzca identidad y coincidencia entre lo uno y lo otro.

En todo caso, el desgarro que puede portar consigo la diferencia no parece que sea lo asumido por Heidegger en lo que refiere al pensamiento del acontecimiento, pues ya vimos cómo había un "unir y dedicar" y un "dejar pertenecer" que a donde llevaba era a la formación de la constelación ser - ser humano en el acto del Ereignis. Pero todo ese acontecer es posible gracias a que hay una inter-cisión (Unter-Schied), una diferencia, un "entre" donde se relacionan, un "lugar" en el que algo se des-encubre y encubre, donde hay resolución (Austrag) y adquieren lo que les es esencial.

Es decir, vemos cómo el Austrag refiere a una brecha originaria que se resuelve en la relación ser-ser humano, es decir, en el Ereignis; y esa es la manera en la que la alteridad radical se inserta en una mismidad, saltando el umbral y resolviendo la brecha. Pero ¿es justo resolver aquello que no se deja tematizar, el Schied? ¿Es apropiado suturar lo que se rompe, lo desgarrado, el Riß?

A pesar de que parezca en un principio que Heidegger se inclina por la resolución del conflicto, es innegable que en sus textos se presenta también la potencia diferencial en todo su esplendor, como interrogando al autor sobre si es realmente factible olvidar ese rumor insistente del desgarro, de la brecha originaria y saturarla con la apropiación ser-ser humano dada en el Ereignis. Por ello se relaciona Austrag con diferencia, donde el -trag nos recuerda que hay un portar, un (sobre)llevar la brecha de la separación originaria, y tal es la marca diferencial que se carga sobre los hombros cada vez que se busca un efectivo reunir y enlazar.

De algo semejante nos habla el desacuerdo existente entre algunos de los traductores de Heidegger al respecto de la palabra, que traducen a veces de formas distintas, como son los casos de "resolución" (Cortés y Leyte), "dirimir" (Vermal), o "acuerdo permanente" (Granel). Asimismo Zimmermann traduce Austragung por

64 Cfr. Vidarte (2006), pp. 15-68. 
"gestación”. Cortés y Leyte argumentan de la siguiente manera: «Se trata tal vez en esta obra del término de más difícil traducción. [...] Con nuestra traducción "resolución", hemos querido recoger tanto el sentido final de un proceso que da lugar a algo nuevo, como el de una decisión adoptada. En Identidad y diferencia, el término "Austrag" está estrechamente ligado a los sentidos de "Lichtung" y "Differenz"; "Austrag" sería algo así como el ámbito, el claro ("Lichtung"), en el que algo se hace evidente, aparece, se resuelve: la diferencia»65. Es decir, el ámbito del umbral, del "entre", donde la brecha originaria se porta con vistas a la gestación de algo nuevo, con vistas a resolver y dirimir el conflicto de la escisión existente.

En todo caso, Austrag mantiene ese carácter de tránsito que hace que podamos dejar caer hacia un lado u otro del umbral la tonalidad que desprende. Jacques Derrida ${ }^{66}$, a este respecto, recuerda y analiza un texto de Heidegger en el que aparecen tres de las palabras fundamentales con las que se mienta la diferencia y que recuerda tal conflicto: "La distinción (Unterscheidung) como "diferencia" (Differenz) quiere decir que entre ser y ente existe un dirimir (Austrag)»67.

\subsection{Identidad y diferencia: (Un)fuge}

Precisamente en Unter-schied 68 , el Schied marca la escisión, el umbral al que ya nos hemos referido, del mismo modo que el par conceptual antitético Díke Adikía, que se volverá relevante en "Der Spruch des Anaximander" y que Heidegger traduce por Fug(e)-Unfug(e).

La discusión parte de la traducción que Heidegger propone para "adikia", que regularmente se traduce por "injusticia", ya que nombra en negativo a la "dike" (derecho, justicia). Si fuese así, Anaximandro haría referencia a la "injusticia presente en cada caso". Pero Heidegger lee que lo que marca la adikía es el no acabar de marchar las cosas bien, la asunción de que existe un desajuste (Unfuge)69. Así, lo que Anaximandro dice es que el presente está desajustado. Pero Heidegger no cree que lo presente pueda estar desajustado, sino que lo que llega a la presencia lo hace entre una llegada y una partida, en un movimiento continuo al que pertenece un ajuste y, al mismo tiempo, la posibilidad de ser desajustado: «Lo presente es lo que mora un tiempo en cada caso. La morada se presenta como llegada transitoria hacia la partida. La morada se presenta entre la procedencia y la partida. Entre esta doble ausencia se presenta la presencia de todo lo que mora. En este 'entre' se ajusta lo que mora un tiempo en cada caso. Este 'entre' es el ajuste (Fuge)»70.

\footnotetext{
65 Heidegger (1988a), p. 107, n. 11.

66 Cfr. Derrida (1998), pp. 339-413.

67 Heidegger (1997), p. 170.

68 Muy utilizado también en Heidegger (1959), passim.

69 Heidegger (2003), p. 327.

70 Ibid.
} 
En todo caso, no se resuelve sin más aquí la problemática, sino que se reconoce que lo presente ("lo que mora un tiempo en cada caso") insiste en la permanencia, más allá del tránsito en el que se hace presente, en el que se ajusta; quiere demorarse y persistir en la morada. Es decir, se empeña en permanecer presente dejando de estar vuelto hacia lo otro presente (das andere Anwesende), haciéndole con ello injusticia ${ }^{71}$ : «Presentándose en el ajuste de la morada, lo presente sale fuera de él y se encuentra, como aquello que mora un tiempo en cada caso, en el des-ajuste. Todo lo que mora un tiempo en cada caso se encuentra en el des-ajuste. A la presencia de lo presente, al eón de los eónta, pertenece la adikía. Encontrarse en el desajuste sería entonces la esencia de todo lo presente» ${ }^{72}$.

Entonces, para Heidegger parece que el mantener la apertura hacia lo otro donde, como veremos ahora, se da el Ereignis es el ajuste (Fuge), el acuerdo (Fug), y al mismo tiempo, el intento de permanecer en la presencia, de intentar negarle al tránsito su carácter, es aquello desajustado (Unfuge), el desacuerdo (Unfug).

Por el contrario, no se lee en Anaximandro que lo presente se pierda en la adikía, sino que en relación con el desajuste al que pertenece lo presente, hay un "dar", un "dejar pertenecer", que ajusta, que ensambla la morada de lo presente. Esto Heidegger lo lee en didónai diken del siguiente modo, que matiza asimismo lo dicho anteriormente: «Lo presente un tiempo en cada caso se presenta en la medida en que mora y, morando, surge y perece, consiguiendo el ajuste (Fuge) de la transición entre procedencia y partida. El permanecer de la transición que mora en cada caso es la permanencia, que concilia acuerdos, de lo presente. No consiste precisamente en la mera persistencia. No cae en manos del des-ajuste (Un-fuge). Repara (verwindet) el des-acuerdo (Un-fug). Morando en su morada, lo que mora un tiempo en cada caso deja que su esencia, como presencia, pertenezca al acuerdo (Fug). El didónai nombra este dejar pertenecer» 73 . Es otra manera de referirse al tránsito, al "entre", a la brecha, al umbral en el que figuran tanto el acuerdo como el desacuerdo, el ajuste como el desajuste. Por tanto, cruzar el umbral para tener una morada en la presencia, y olvidarse del tránsito, no significa tener una morada propia y auténtica, sino un permanecer injusto y desajustado.

De acuerdo con esto, la separación, la escisión o la diferencia se dan en el umbral, en la apertura, en el "entre" en el que aparecen las cosas, que a su vez se dan en las figuras de la reunión y el recogimiento, siempre dentro de la simultaneidad del Ereignis.

Más allá de ello, recordando lo que anteriormente decíamos sobre la historia de la metafísica como aquella historia que muestra cómo se piensa el ser en cada momento por cada pensador central, vemos cómo en la parte final de "Der Spruch

\footnotetext{
71 Op. cit., p. 328.

72 Ibíd.

73 Op. cit., p. 329.
} 
des Anaximander", Heidegger recuerda la ensambladura, la juntura, el acuerdo que presupone esta unificación de la historia de la metafísica en relación con la presencia, proponiendo la señalización nominal de otros presentes que se van dando ajuste los unos a los otros: «La enérgeia, que Aristóteles piensa como el rasgo fundamental de la presencia, de eón; la idéa, que Platón piensa como el rasgo fundamental de la presencia; el Lógos, que Heráclito piensa como rasgo fundamental de la presencia; la Moîra, que Parménides piensa como rasgo fundamental de la presencia; Khreón, que Anaximandro piensa como lo que se presenta en la presencia, nombran, todos ellos, lo mismo. En el oculto reino de lo mismo se encuentra la unidad del uno unificador, el Hén pensado por cada pensador a su manera» 74 .

Ahora bien, visto ya cómo Heidegger de algún modo se inclina hacia la resolución identitaria y unificadora en el Ereignis, podríamos ver en la misma línea de qué forma se da la simultaneidad que Heidegger asume entre el ser -el aparecer del acontecimiento- y el existente humano, que como vimos es pensante.

Lo primero a decir sería recordar lo ya señalado: que Heidegger huye de lo trascendental, intentando pensar de otro modo. Y para ello piensa una simultaneidad en la presencia, en el hacerse presente. La simultaneidad no se da entre entes, sino entre una suerte de fuerzas que se limitan unas a otras, y por eso el acontecimiento es pensado por Heidegger como una lucha en la que esas fuerzas encuentran un equilibrio que las lleva a aparecer. El caso de la historia de la metafísica es relevante en este sentido, pues allí la relación entre el ser y el pensador en el momento del acontecimiento es pensado por Heidegger como respuesta (del pensador) a una llamada del ser. El responder es pensar (denken), y el responder es también agradecer (danken) al don de ser y tiempo del Ereignis.

Heidegger, en el diálogo de Serenidad, identifica esta correspondencia con la esencia del pensar:

P. Lo noble longánime sería el puro reposo-en-sí de aquel querer que, renunciando al querer, se ha comprometido (Sich eingelassen) con lo que no es una voluntad.

E. Lo noble sería la esencia del pensar (Denken) y por ende del agradecer (Danken).

P. De este agradecer que no agradece primeramente algo, sino que se limita a agradecer el hecho de que le esté permitido agradecer.

E. Con esta esencia del pensar habríamos encontrado lo que buscamos 75 .

Y el problema que acarrea esta correspondencia es que, al pensar la llamada y la respuesta como simultáneas, o el dar y el recibir-agradecer-en los mismos términos, nos encontramos con la problemática de la performatividad de la ley, de la que hablaremos a continuación.

\footnotetext{
74 Op. cit., p. 342.

75 Heidegger (1988b), pp. 74-75.
} 
De acuerdo con esto hay una jerarquía presente de alguna forma en esa simultaneidad, no es simplemente un "pertenecer común", sino una transmisión vertical de estructura llamada-respuesta que sucede en un instante. Al prevalecer la identidad sobre la diferencia, se impide que haya un diferir que separe en dos momentos el dar-recibir, y también que haya más actores en juego, por ejemplo, dos seres humanos. Por el contrario, al ser una simultaneidad presente, su aparecer, su hacerse presente, es de algún modo lo que hace el acontecimiento.

\subsection{Performatividad en el Ereignis}

Ésta sería una de las consecuencias en el pensamiento de Heidegger de pensar el "háma" en la presencia, en el aparecer, en vez de pensar el acontecimiento fuera del valor de presencia.

El performativo en Heidegger sería el de la autoridad, el performativo soberano: si hay una llamada y una respuesta inmediata, hay una orden, y esa orden implica una autoridad subyacente cuyos implicados asumen y aceptan como tal. Así, la performatividad toma la forma de lo simultáneo, ya que en el momento en el que la orden se da, se hace lo que ella implica por la asunción de la autoridad que la orden porta. Un ejemplo lo vemos aquí: «El advenimiento apropiador (Ereignis) confiere a los mortales la morada en su esencia para que puedan ser los hablantes. Si por "ley" entendemos el recogimiento de lo que deja venir en presencia cada cosa en lo suyo propio, o sea, que lo deja pertenecer a su pertenecimiento, entonces el Ereignis es la más simple y gentil de todas las leyes [...]. Con todo, el Ereignis no es una ley en el sentido de una norma que planea en algún lugar sobre nosotros; no es un decreto que ordena y regula un proceso. I

El Ereignis es la ley, en la medida en que congrega los mortales a la apropiación de su ser propio y los retiene en él» ${ }^{76}$.

De este modo, la experiencia del acontecimiento es esa transmisión de significatividad simultánea entre el ser y el Dasein. Cuando el ser me llama, yo respondo, y las dos cosas son lo mismo, son simultáneas. El acontecimiento en Heidegger sería esa simultaneidad.

Asimismo, el acontecimiento es político por su performatividad intrínseca, porque cambia lo que había, y porque la expectativa ante el acontecimiento es un estar haciendo algo para que ocurra -en la medida en que no se puede "hacer" nada, que la acción de un sujeto lo anularía-, pues la apertura del pensar es ya una suerte de acción.

Por eso, aunque Heidegger intenta evitar la trascendentalidad, quizás no lo consigue del todo, ya que es la respuesta ante la "ley" la que le da al ser humano su ser

76 Heidegger (1959), p. 259. 
propio, es en el responder cuando verdaderamente soy un ser humano. Entonces el ser como Ereignis es la condición de posibilidad de mi ser, me hace ser lo que soy, y de paso, me hace poder decir(lo), mi decir (Sagen) es un mostrar (Zeigen). Y de este modo mi decir ya está mostrando -transfiriendo el "sentido" que he recibidode forma inmediata. Por ello puede considerarse que es el pensador el que inicia el acontecimiento y que, tomando la terminología de "Der Ursprung des Kunstwerkes" - uno de los primeros pasos decisivos de cara al pensamiento del Ereignis-, el resto son "cuidadores"77.

\section{Conclusión: el acontecimiento acaece (das Ereignis ereignet)}

Por último, el pensamiento del Ereignis aparece en Heidegger de nuevo tematizado en 1962 en la obra Zeit und Sein para ser abordado a partir del ser y el tiempo, intentando cerrar con ello lo planteado en Sein und Zeit treinta y cinco años atrás.

En un principio Heidegger ya hace otro tratamiento de estos elementos al reconocer que «en lo que respecta a la cosa o cuestión "ser" y en lo que respecta a la cosa o cuestión "tiempo", nos mantenemos ojo avizor. No decimos: el ser es, el tiempo es, sino: se da el ser y se da el tiempo»78.

Con "se da" se traduce la expresión Es gibt, lo que nos acerca a la cuestión del don: «A un dar que sólo da su don y él mismo se mantiene retirado, a un dar así lo denominamos: enviar (Schicken) ${ }^{79}$. Según este sentido de dar, el ser que se da es lo enviado (Das Geschickte)»80. Esto nos lleva a la idea de destino (Geschick) y, de nuevo, a un camino de necesidad, donde hay una transmisión jerárquica de significación o, al menos, una vía que no se escinde.

En cuanto al tiempo, Heidegger vuelve al concepto de "estar presente" (Anwesen). Con él se busca indicar que el ser humano «recibe como don el estar presente que Se da (es gibt), mientras percibe lo que aparece en el dejar estar presente» 81 . Y este recibir, precisamente, no llega al ser humano solamente en el tiempo presente, sino que de alguna forma también llega -y también se percibe- en el pasado y en el futuro. De este modo, Anwesen sería un tender, un alcanzar, un proporcionar (Reichen $)^{82}$ que está presente en las tres dimensiones temporales $\mathrm{y}$, por

\footnotetext{
77 Heidegger (2003), p. 54 y ss.

78 Heidegger (1969), pp. 4-5.

79 Aquí, Manuel Garrido -traductor de la versión española del texto publicada en la editorial Tecnos en 1999- traduce directamente por "destinar".

80 Op. cit., p. 8.

81 Op. cit., p. 12.

82 Seguimos la traducción propuesta por Berciano en Berciano (1991a). Garrido traduce por "regalía". La versión francesa es "porrection", de donde se derivaría "porrección", algo así como «una donación
} 
tanto, sería como una cuarta dimensión en la que se daría la simultaneidad del Ereignis, uniendo y manteniendo las tres formas temporales ${ }^{83}$.

Del mismo modo, el ser humano no es causa del tiempo, no es él el que da tiempo, ya que el ser humano se encuentra siempre ya en una apertura originaria de tiempo-espacio, que precisamente se da en ese proporcionar que marca la palabra Reichen: «El tiempo no es ningún producto del ser humano, el ser humano no es ningún producto del tiempo. Aquí no se da ningún producir. Se da sólo el dar [...]»84.

La reflexión de Heidegger ha llegado así a dos conclusiones: con respecto al "dar ser" el dar remite a un envío y a un destino. Con respecto al "dar tiempo", el dar proporciona la simultaneidad de las tres formas temporales en una cuarta que las unifica. Heidegger aún añade que en ese dar ser y tiempo ambos son determinados o constituidos en lo suyo propio (Eigenes). «A lo que determina a ambos, ser y tiempo, en lo que tienen de propio (Eigenes), esto es, en su recíproca copertenencia, lo llamamos el acontecimiento (das Ereignis)»»85. Y así llegamos al concepto de acontecimiento como lo que determina al tiempo y al ser en lo suyo propio. Es el Ereignis lo que proporciona la apertura en la que se dan el ser y el tiempo. Y por ello es un acaecer, un acaecer en el que lo que se da se pertenece a sí mismo y a la apertura que le proporcionó el llegar a darse. Así, el acontecimiento es lo que da la copertenencia del ser y el tiempo.

Pero del mismo modo, el Ereignis no refiere únicamente a la resolución en lo propio de aquello que se da conjuntamente, sino que a él también le pertenece un ocultarse, marcado precisamente en el pasado - que ya no es presente- y el futuro -que aún no lo es-. Es decir, también en el acontecimiento se oculta el ser y el tiempo. De ahí que «al Ereignis como tal pertenezca la expropiación (Ent-eignung)»86, o lo que es lo mismo, un peculiar ocultarse.

Valga esto como muestra de que Heidegger en todo momento es consciente de la presencia de dos tonalidades en sus escritos, la que tiende al acuerdo, a la juntura, al ensamblamiento, al ajuste, a la desocultación, a la propiedad, en fin, a la identidad; y la que lo hace a la adikia, Un-fuge, Unter-schied, Enteignung, en fin, diferencia.

Heidegger se pregunta, una vez más, al final del escrito qué es el acontecimiento. «¿Qué queda por decir? Sólo esto: el acontecimiento acaece (das Ereignis ereig$n e t) » 87$. Y con esto de nuevo Heidegger se remite al antiguo concepto griego de alétheia ${ }^{88}$, aquella desocultación que ocurría en tanto en cuanto algo seguía permaneciendo oculto.

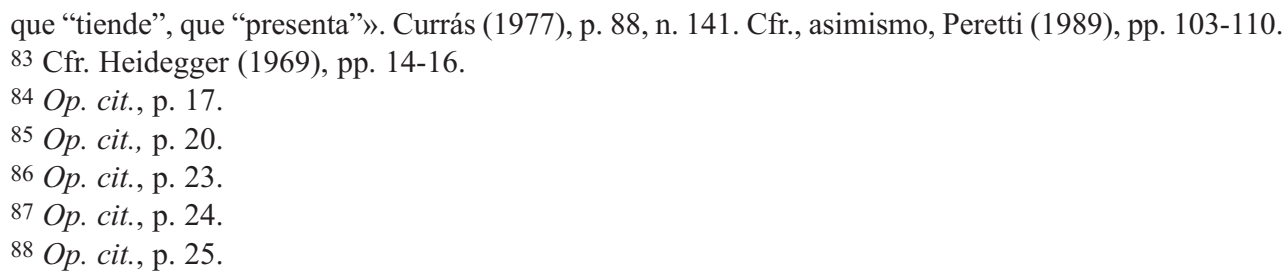




\section{Referencias bibliográficas}

Aristóteles (1982): Tratados de lógica (Órganon) I. Categorías. Tópicos. Sobre las refutaciones sofisticas, Madrid, Gredos.

Aristóteles (1988): Tratados de lógica (Órganon) II. Sobre la interpretación. Analíticos primeros. Analíticos segundos, Madrid, Gredos.

ARISTÓteles (1998): Metafísica, Madrid, Gredos.

AubenQue, P. (1974): El problema del ser en Aristóteles, Madrid, Taurus.

Berciano, M. (1991a): Superación de la metafísica en Martin Heidegger, Universidad de Oviedo.

Berciano, M. (1991b): "El evento (Ereignis) como concepto fundamental de la filosofía de Heidegger", en Naturaleza y gracia, 1-2, pp. 91-118.

Currás, Á. (1977): "Heidegger: el arduo sosiego del exilio", en Logos. Anales del seminario de metafísica, 12, pp. 59-94.

Derrida, J. (1998): Politicas de la amistad. El oído de Heidegger, Madrid, Trotta.

HeidegGer, M. (1954): "LOGOS (Heraklit, Fragment 50)", en Vorträge und Aufsätze, Tübingen, Neske, pp. 199-221.

Heidegger, M. (1959): Unterwegs zur Sprache, Stuttgart, Klett-Cotta.

Heidegger, M. (1969): “Zeit und Sein“", en Zur Sache des Denkens, Tübingen, Max Niemeyer Verlag, pp. 1-25.

Heidegger, M. (1971): Was heißt Denken?, Tübingen, Max Niemeyer Verlag.

HeIdEgGER, M. (1977): Sein und Zeit, Gesamtausgabe 2 (en adelante, GA), Vittorio Klostermann. Frankfurt am Main.

HeIDEGGER, M. (1988a): Identität und Differenz / Identidad y diferencia, Barcelona, Anthropos.

HeIDEgGer, M. (1988b): Serenidad, Barcelona, Serbal.

HeIdegger, M. (1994): Beiträge zur Philosophie (Vom Ereignis), GA 65.

HeIDEGGER, M. (1997): Nietzsche II, GA 6.2

HeIdegger, M. (1999): Zur Bestimmung der Philosophie, GA 56/57.

Heidegger, M. (2002): "Was heißt Lesen?", en Aus der Erfahrung des Denkens, GA 13, pp. 111-116.

Heidegger, M. (2003): Holzwege, GA 5.

HeIDEGGER, M. (2004): Wegmarken, GA 9

Hölderlin, F. (2002): Gedichte / Antología poética, Madrid, Cátedra.

Martínez MarzoA, F. (1999): Heidegger y su tiempo, Madrid, Akal.

Martínez MarzoA, F. (2000a): Historia de la filosofía, Madrid, Istmo.

Martínez MarzoA, F. (2000b): Historia de la filosofia antigua, Madrid, Akal.

Peretti, C. de (1989): Texto y deconstrucción, Barcelona, Anthropos.

Polt, R.: "Ereignis" (2005), en H. L. Dreyfus y M. A. Wrathall (eds.), A companion to Heidegger, Oxford, Blackwell, pp. 375-391. 
Rolli, M. (ed.) (2004): Ereignis auf Französisch. Von Bergson bis Deleuze, München, Wilhelm Fink Verlag.

SpinosA, C. (2005): "Derrida and Heidegger: iterability and Ereignis", en H. L.

DreYfus, y M. A. Wrathall (eds.), A companion to Heidegger, Oxford, Blackwell, pp. 484-510.

Vallega-Neu, D. (2010): "Ereignis: the event of apropiation", en B. W. Davis (ed.): Martin Heidegger: Key concepts, Durham, Acumen, pp. 140-154.

VIDARTE, P. (2006): "Heidegger, la lectura como reunión", en ¿Qué es leer? La invención del texto en filosofía, Valencia, Tirant lo Blanch, pp. 15-68.

Abraham Rubín

Departamento de Filosofía y Filosofía moral y política

Universidad Nacional de Educación a Distancia

arubin@edu.xunta.es 